\title{
City size and competitiveness for the cities of São Paulo: a spatial statistics analysis*
}

Paulo Costacurta de Sá Porto**

Francisco Marcelo Rocha***

\section{ABSTRACT}

The objective of this article is to develop a competitiveness index for the 645 cities of the state of São Paulo, Brazil (ICM-SP). We ranked cities according to the overall competitiveness index and each one of the five dimensions of competitiveness: urban/environmental, sociodemographic, fiscal/institutional, economic and innovation. Additionally, we performed an Exploratory Spatial Data Analysis (ESDA) in the ICM-SP. Our results show that cities with similar competitiveness levels tend to locate near each other, which show the presence of spatial clusters in the state of São Paulo. The cluster of cities with high competitiveness spill over from the São Paulo Metropolitan Region to the Campinas Metropolitan Region, reaching another cluster around Ribeirão Preto. Moreover, we found that cities with the highest competitiveness indexes are mostly midsized cities, in general part of metropolitan areas led by one or more large cities. Regarding the five dimensions of competitiveness, we noted that cities with high urban/environmental and sociodemographic competitiveness are composed mostly of medium sized cities. Smaller cities tend to perform better in the fiscal/institutional dimension, whereas larger and midsized cities tend to excel in the economic dimension. In the innovation dimension, we noticed a cluster of cities with high performance which spillover

\footnotetext{
* We would like to thank Carlos Roberto Azzoni and Veneziano Araujo for comments and suggestions on different versions of this paper, and Alexandre Rosenberg for research assistanship.

** Federal University of São Paulo (Unifesp), Osasco (SP), Brasil. E-mail: sa.porto@unifesp.br.

*** Federal University of São Paulo (Unifesp), Osasco (SP), Brasil. E-mail: fmmrocha@unifesp.br.
} 
from São José dos Campos to São Paulo and to Campinas, plus another cluster surrounding Ribeirão Preto.

KeYwords | City Competitiveness; Competitiveness Index; Exploratory Spatial Data Analysis; Innovation

JEL CODE | R11; R15; R58

\section{Tamanho da cidade e competitividade dos municípios de São Paulo: uma análise de estatística espacial}

\section{RESUMO}

O objetivo deste artigo é desenvolver um índice de competitividade para os 645 municípios do estado de São Paulo (ICM-SP). As cidades foram classificadas de acordo com um índice de competitividade geral e segundo cinco dimensões da competitividade. Além disso, foi realizada uma análise espacial de dados exploratória (AEDE) com os dados do ICM-SP. Os resultados mostram que cidades com níveis de competitividade semelhantes tendem a se situar próximas umas das outras, o que demonstra a presença de clusters espaciais no estado de São Paulo. O aglomerado de cidades com alta competitividade se estende da Região Metropolitana de São Paulo até a Região Metropolitana de Campinas, chegando a um cluster em torno de Ribeirão Preto. Verificou-se também que as cidades com os maiores índices de competitividade são, na sua maioria, de médio porte, em geral parte de áreas metropolitanas lideradas por uma ou mais cidades grandes. Quanto às cinco dimensôes da competitividade, aquela referente à alta competitividade urbana/ambiental e sociodemográfica engloba, principalmente, cidades médias. Já as menores tendem a ter um melhor desempenho na dimensão fiscal/institucional, enquanto as grandes e médias tendem a se destacar na dimensão econômica. Na dimensão da inovação, observa-se um conjunto de cidades com alto desempenho que se espalham de São José dos Campos para São Paulo e para Campinas, além de um outro cluster em torno de Ribeirão Preto.

PALAVRAS-CHAVE | Competitividade Municipal; Índice de Competitividade; Análise Espacial de Dados Exploratória; Inovação

Códigos-JEL | R11; R15; R58 


\section{Introduction}

Companies are increasingly involved in a fiercer competition on global product and service markets. In these times of deepening globalization, the integration of goods and services markets, location sites of economic activities, and production factors, such as technologies and information, affects differently the regions in which those companies are located. As these regions are involved in the globalization process to a different extent depending on their structure and specialization (CAPELLO; FRATESI, 2013, p. 15), their regional governments have been trying to create more favorable conditions for the economic agents in their localities (KOURTIT; NIJKAMP; SUZUKI, 2013, p. 67).

For Zhang (2010), businesses rely on a favorable local environment to become more competitive. Cities that are able to provide a better business environment are likely to have more competitive private businesses. Thus, local policy makers need to understand the factors that private businesses regard as important, and pursue policies to improve the local business environment and promote local economic development.

But how can one view and measure the potential and performance of these cities? Porter (1990) created a theoretical framework in which the determinants of city competitiveness are related to four sets of attributes that cities might possess (Porter's "Diamond" model): factor conditions; demand conditions; related and supporting industries conditions; and strategy, structure and rivalry conditions. Moreover, these four sets of conditions are influenced by chance and by government (national, regional and local) policies.

On the other hand, there have been many different proposals to create a classification or ranking of cities based on their actual competitiveness performance (such as WORLD ECONOMIC FORUM, 2014; MBC 2006; EIU 2013; FIRJAN, 2014; MEINERS et al. 2013). In general, firms seek to be located in cities with good economic and financial structures (economic dimension), a skilled and productive labor force (sociodemographic dimension), good infrastructure (urban dimension), and strong institutions and favorable fiscal policies (fiscal/institutional dimension) (ZHANG, 2010, p. 94).

Another important dimension of competitiveness is innovation. Many of the new industries of the twenty first century increasingly depend on the generation of knowledge through creativity and innovation. Achieving success in those industries requires that cities support such knowledge-intensive firms, housing other knowledge- 
creating institutions (such as universities and research centres) in a fierce inter-urban competition game (LANDRY; BIANCHINI, 1995; FLORIDA, 2002). Also, there is strong evidence that local, "territorial capital" factors, such as the share of human resources working in science and technology innovation, play an important role in explaining regional growth (CAPELLO; FRATESI, 2013).

The objective of this article is to develop a competitiveness index for the 645 municipalities of the state of São Paulo, Brazil (Índice de Competitividade dos Municípios de São Paulo, or ICM-SP). Similar to Zhang's (2010) methodology, we constructed the ICM-SP across four dimensions (urban, sociodemographic, fiscal/ institutional and economic), but we included a new, fifth dimension: innovation. Additionally, we included environmental indicators to the urban dimension (so it became the urban/environmental dimension), and we included institutional indicators to the fiscal/institutional dimension. Using data from 2011 and 2012, we used 46 indicators spread throughout the five dimensions. After calculating the index, we then ranked cities according to the overall competitiveness index, and by each one of the five dimensions of competitiveness.

Moreover, we seek to contribute to the debate on the role of city size in competitiveness. Particularly, we tested the hypothesis that today's medium sized cities usually have higher competitiveness than large cities, as it has been the case in several countries recently (DIJKSTRA et. al, 2013; PARKINSON et al., 2014; CAMAGNI et al., 2014). To do so, we performed an Exploratory Spatial Data Analysis (ESDA), using the data for the Competitiveness Index for the municipalities of the state of São Paulo (ICM-SP) in order to detect and understand the spatial interactions present in the ICM-SP. We tested the hypothesis that competitiveness is autocorrelated in space throughout the cities of the state of São Paulo, that is, cities in this state with similar competitiveness tend to be located near each other. We evaluated the spatial patterns of the overall competitiveness index for all cities and for each one of the five dimensions of competitiveness.

The contribution of this article is fourfold. First, it provides a city competitiveness index which includes an innovation dimension, as well as environmental and institutional variables, which other measures, such as the Firjan Municipal Development Index (FIRJAN, 2014) and Zhang's (2010) index, did not provide. Also, it provides a competitiveness index for the municipalities of the state of São Paulo, which was not previously available. This is important as São Paulo is the largest regional economy in Brazil since at least the 1940s (CANO, 1998, p.306). We also provide evidence of the role of city size in competitiveness and of 
the presence of spatial spillovers in the state of São Paulo. Finally, the application of the ICM-SP methodology in São Paulo also presents the cities with the best competitive environments for business development, and it serves as a reference for the promotion of local development policies.

The paper is structured as follows; In the next section, we review recent literature on the determinants of competitiveness and on competitiveness indexes. In section 3 , we present the methodology and data for the construction of a Competitiveness Index for the 645 cities of the state of São Paulo (ICM-SP) and for the Exploratory Spatial Data Analysis (ESDA). Following that, section 4 includes our results for the ICM-SP and for the ESDA. In the last section, we present our conclusions and suggestions for future work.

\section{City competitiveness}

In this section we briefly review the existing literature on city competitiveness. We start with a discussion on the definition and main determinants that influence city competitiveness.. Then, we review the indexes that have been constructed so far in order to measure competitiveness at the national, state and city levels.

\subsection{Determinants of city competitiveness}

The very notion of competitiveness is complex and contentious; researchers on the issue are far from a consensus on what is meant by the term and how it can be measured (KITSON et al., 2004, p.991). Indeed, Begg (1999, p. 798) states that there are different definitions of competitiveness, depending on the focus of interest. It could be defined at the firm level, for example, as the ability to meet customers' needs more efficiently and more effectively than other firms. It could also be defined from the standpoint of a nation, and it could also be defined at the urban or city levels as the capacity of a city to compete with others to attract investments and to create jobs locally, shaped by the interplay between the attributes of cities and the policy choices and institutions created by local policy makers.

In turn, Porter (1990) noted that competitive firms in each international sector were located in a small number of countries (as well as regions and localities). $\mathrm{He}$ also pointed out that competitive advantages are often "created" and held in a highly localized process. According to him, the influence of a nation or a region in a firm's competitiveness is given by four sets of attributes that it might possess (Porter's 
Diamond model): 1) factor conditions, which relate to the endowment of resources (human, physical, capital, knowledge and infrastructure) that a nation or a region possesses; 2) demand conditions, which relate to the quality of the domestic buyer market; 3) related and supporting industries conditions, which have to do with the presence of domestic suppliers and related firms to a particular industry; and 4) strategy, structure and rivalry conditions, which are related to the environment in which firms are born, how they are organized and managed, and the way in which internal rivalry occurs in the domestic industry.

Moreover, according to Porter (1990), there are two sets of factors that work locally and influence the other four sets of conditions: 1) chance, which is related to the events that happen fortuitously and are beyond previously forecast scenarios; and 2) government (national, regional and local) policies, which are deliberate actions by the government that influence the conditions of the four sets of determinants. Porter (1990) argues that the Diamond is a dynamic system, in a sense that its attributes work interconnectedly (one factor influences the other) and evolve over time. He also points out that if companies are to compete in the global market, advantages are necessary throughout the Diamond to obtain and maintain competitive advantage in their industries. Thus, government policies that strengthen regional advantages throughout the determinants can influence the competitiveness of firms.

Zhang (2010, p. 2) defines competitiveness as the set of institutions, policies, and other factors that determine the level of productivity of a city or a region. With productivity as its basic measure, competitiveness encompasses connotations that include both the level of economic growth and the potential for sustained growth. Competitive local economies not only produce higher income for their cities, but are also more likely to grow faster over the medium to long term.

The author further argues that location matters, as some cities provide better locations than others for private businesses to be more competitive. To become so, businesses rely on a favorable local environment, where they can achieve (static) cost efficiency. Besides, cities need to continually upgrade and innovate to achieve sustained growth. Therefore, competitiveness is a dynamic concept. For the author, cities compete against each other, and those that can provide a better business environment are likely to have more competitive private businesses. Thus, local policy makers need to understand the factors that businesses regard as important, and pursue policies to improve the business environment and promote local economic development. 
For Capello and Fratesi (2013, p. 18-19), regional growth and competitiveness are largely supply-side phenomena, based on general rules and institutional frames, nourished by the internal entrepreneurial capabilities of regions and places and by the local capability of efficiently exploiting existing resources. They are the result of internal forces and endogenous capacity of a region to grow, and are dependent on creatively exploiting its "territorial capital", enriching it in the right ways and setting appropriate priorities to local and regional policies, as well as "tapping" and mobilizing previously "untapped" assets of its territorial capital. The authors define territorial capital as the set of localised assets - natural, human, artificial, organizational, relational and cognitive - that constitute the competitive potential of a given territory. The factors that comprise endogenous territorial assets are increasingly non-material factors linked to knowledge, culture, taste and creativity, and are accumulated in a highly localized matter, depending very much on local aspects.

According to the authors, exogenous forces that reach a local economy from outside, such as foreign productive capital, also play an important role. Moreover, national factors such as institutional, organizational and economic variables also play a role. Altogether, endogenous and exogenous factors give rise, in a cumulative selfreinforcing mechanism, to a process of local growth (CAPELLO, FRATESI 2013, p. 22-28). They empirically estimated a multivariate regression model for European regions which included regional growth as the dependent variable. They included national growth and foreign direct investment flows as outside force variables, as well as territorial capital variables such as growth effects induced by the regional geographical position; degree of innovation; infrastructure endowments; regional specialisation in high-value functions; agglomeration economies; and presence of public funds. They concluded that regional territorial capital assets are fundamental for explaining the capacity of a local area to grow more than its nation. They also showed that the national component of growth and the presence of foreign direct investment play an important role in accounting for regional growth.

Camagni (2002) states that competitiveness at the 'territorial' level is very different to that among countries. In order to export, local firms have to show a higher competitiveness with respect to external firms and territories. Thus, cities and regions compete on the basis of an absolute advantage principle, and not of a comparative advantage principle. This means that there is no eficient, automatic mechanism to grant each territory some role in the international division of labour, whatever its relative performance. Therefore, weak and lagging territories (in terms of competitiveness of the economic fabric, internal/external accessibility, quality of 
the human and environmental factors, internal synergy and learning capability) risk exclusion and decline (CAMAGNI, 2002, p.2407).

On the other hand, he mentions that this competitiveness resides in dynamic elements, allowing the continuous re-creation of the local advantage, through a flow of radical and incremental innovation. The sources of territorial competitiveness are more and more two factors: 1 ) increasing returns linked to cumulative development processes and the agglomeration of activities; 2) advantages strategically created by single firms, territorial synergies and cooperation capability enhanced by an imaginative and proactive public administration, externalities provided by local and national governments and the specificities historically built by a territorial culture. Thus, those created advantages are open to the proactive, voluntary action of local communities and their governments (CAMAGNI, 2002, p.2405).

Albuquerque (2001) perceives the firm as surrounded by a territorial competitive environment, that is, there are several exogenous factors that determine a company's position in the competitive market dispute. These factors include health, housing and leisure systems; educational system and training of human resources; innovative cultural environment; quality of the environment; efficient government structures; a science, technology and innovation system; financial system and access to credit; job market; business development services; and allocation of basic infrastruture. Thus, it is important to consider the territorial environment in order to determine the performance of firms, for it defines their systemic competitiveness (ALBUQUERQUE, 2001).

Finally, Da Mata et al. (2007) set up a model for the Brazilian context that considers both demand and supply side variables, with a reduced form equation that seeks to explain city growth using a dataset of 123 Brazilian agglomerations. They found that increases in rural population supply, and improvements in interregional transport connectivity and education attainment of the labor force have strong impacts on city growth. Both labor force quality improvements and base period educational attainment matter significantly for growth. In terms of local characteristics, the authors found that local crime and violence and a higher representation of public industrial capital in the city lower city growth rates (DA MATA et al. 2007, p.252).

\subsection{City competitiveness indexes}

Competitiveness indexes have been widely used to identify and benchmark the competitive and productive potential of nations, regions and cities. In general, these 
indexes show the drivers of competitiveness in multiple dimensions. There is a wide variety of those indexes which have been used in different contexts. For example, the World Economic Forum compiles annually a competitiveness ranking at the national level among 144 participating countries (WEF, 2014). This is based on an index (Global Competitiveness Index - CGI) which comprises 12 pillars of competitiveness, and countries have been ranked among those pillars for more than thirty years.

At the regional level, Annoni and Dijkstra (2013) constructed the Regional Competitiveness Index (RCI) for the European regions. Using data at the regional (NUTS2 European classification) level, they explain competitiveness according to eleven factors, or pillars, which use 73 indicators. In turn, the Economist Intelligence Unit has compiled since 2011 a Business Operating Environment Index for the 27 Brazilian states (CLP, 2013), which includes eight major factors that affect business operations in Brazilian states. Besides, the Competitive Brazil Movement (MBC, 2006) created the ICE-F, a competitiveness index for the Brazilian states also. It is based on Porter's (1990) Diamond model methodology and it includes three dimensions of competitiveness.

At the city level, The Economist Intelligence Unit (EIU, 2013) assembled a competitiveness index for the 120 largest cities in the world, ranked according to eight distinct thematic categories: economic strength; physical capital; financial maturity; institutional character; human capital; global appeal; social and cultural character; and environment and natural hazards. There is also the Firjan Municipal Development Index (IFDM), built by the Federation of Industries of the state of Rio de Janeiro (FIRJAN, 2014). It ranks the current state of development of Brazilian municipalities along four dimensions: education, health, income and employment. Moreover, the Index of Municipal Development of Micro and Small Companies (ID-MPE) was created to guide the development of local strategies and policies for the implantation and growth of small local businesses (MEINERS et al., 2009). It has three dimensions: Business Environment, Consumer Market Environment and Institutional Environment, which include a total of 18 indicators. The authors applied the index to cities in the Brazilian state of Paraná in and performed a spatial analysis on the data (MEINERS et al., 2013); their results suggested the existence of spatial auto correlation in the data, indicating the presence of spatial clusters of cities in Paraná.

Finally, Zhang (2010) looks at the factors that contribute to economic growth at the city level and that determine competitiveness for Brazilian cities. The author evaluates the competitiveness of Brazilian cities by using four dimensions: urban, sociodemographic, fiscal/institutional, and economic. Each dimension incorporates 
a series of variables using census data for the year 2000. Also, he uses the principal component analysis (PCA) method to construct the index and its four dimensions, and presents results for three groups of cities: small (up to 50,000 inhabitants), medium (between 50,000 and 300,000 inhabitants) and large (over 300,000 inhabitants).

\section{Methodology}

In this section we present the methodology and the data for the construction of the Competitiveness Index for the 645 cities of the state of São Paulo (ICM-SP) and for the Exploratory Spatial Data Analysis (ESDA).

First, we start with the methodology for the construction of the ICM-SP; we used a methodology similar to the one used in Zhang (2010). Note, however, that we improved upon that methodology in that we added a fifth dimension, innovation. In order to justify the inclusion of this variable, we consider that, as argued by Camagni (2002, p.2397), local competitiveness increasingly resides in dynamic elements through a flow of radical and incremental innovation due to the presence of knowledge spillover effects on the productivity from the activities of individual local firms. Moreover, as data on environmental and institutional indicators has become available, we included them to improve the explanatory capacity of the model; we added natural environmental indicators to the urban dimension (so that it became the urban-environmental dimension), and we included institutional indicators to the fiscal/ institutional dimension. Thus, we have five dimensions to competitiveness: urban/ environmental; sociodemographic; fiscal/institutional; economic; and innovation.

Each dimension tries to capture an important aspect of local competitiveness. The urban/environmental dimension seeks to represent the urban infrastructure and the quality of the natural environment and of urban services. The sociodemographic dimension attempts to describe the labor market conditions (skills and productivity) of cities. The fiscal/institutional dimension tries to capture the strengths of the government and the fiscal environment. The economic dimension attempts to describe the economic and financial structure of the city. The innovation dimension, in turn, seeks to evaluate the ability to innovate and create knowledge locally.

Moreover, we chose 46 indicators, which were spread through our five dimensions. We sought to use the same variables that Zhang (2010) used, but in some cases the data were not available for many cities. We included innovation and knowledge indicators, as well as several institutional and environmental variables that Zhang (2010) did not include. The five dimensions and their comprising variables are listed in Table 1. 
TABLE 1

Variables Used for the Five Dimensions of the Competitiveness Index

\begin{tabular}{ll}
\hline \multicolumn{1}{c}{ 1) Urban/Environmental } & \multicolumn{1}{c}{ 2) Sociodemographic } \\
\hline Urbanization rate & Human Development Index \\
Number of people between 18 and 65 years old & Gini Index \\
$\%$ of houses with waste collection & Child mortality rate (up to 5 years old) \\
$\%$ of houses with sewerage & Life expectancy \\
$\%$ of houses with piped water & \% of illiteracy \\
$\%$ of houses with lighting & \% of indigent people \\
Inpatient beds per thousand inhabitants & \% people receiving up to 1/2 of \\
Registered physicians per thousand inhabitants & minimum wage \\
Nursing technicians per thousand inhabitants & Population growth 2000-2010 \\
Number of homicides per 100,000 inhabitants & \\
$\%$ of houses with computers & \\
$\%$ of houses with phone lines (fixed) & \\
$\%$ of houses with phone lines (mobile) & \\
Inhabitants over Total of Vehicles & \\
Presence of structure for environmental management & \\
Presence of local environmental fund & \\
Presence of local environmental legislation &
\end{tabular}

\begin{tabular}{ll}
\hline \multicolumn{1}{c}{ 3) Fiscal/Institutional } & \multicolumn{1}{c}{ 4) Economic } \\
\hline City revenue per capita & Per capita income \\
City expenditure per capita & Average wage (monthly) \\
Municipal Participation Fund transfer amount & \% GDP secondary sector \\
City investments (excluding federal and state investment) & \% GDP tertiary sector \\
over GDP & City GDP per capita \\
Payroll expenditure over city revenue & Per capita savings \\
City tax burden & Credit operations per capita \\
Presence of local urban policy & Number of banks per 100,000 \\
Presence of local environmental legislation & inhabitants \\
\hline
\end{tabular}

\section{5) Innovation}

\begin{tabular}{ll}
\hline Patents per 100,000 inhabitants & Innovative Potential Index* \\
Engineers and researchers per 10,000 employees & $\%$ of population with university degree \\
\hline
\end{tabular}

Sources of data: IBGE (2013); Fund. SEADE (2011); Fund. J.Pinheiro/PNUD/IPEA (2013). INPI (2011); RAIS (2013). * This index is defined in Gois and Azzoni (2016). 
Unlike Zhang's article, which calculated the index for all Brazilian cities, we chose to use only the cities of the state of São Paulo as our sample, as São Paulo is the largest regional economy in Brazil in all of the index dimensions. We also used more recent data. Whereas Zhang (2010) used census data for the year 2000, we used data for 2011 and 2012, from many sources (IBGE, 2013; SEADE, 2011; Fundação João Pinheiro/PNUD/IPEA, 2013; INPI, 2011); RAISMTE, 2013). Besides, we chose to use the municipality as the level of analysis, as opposed to the minimum comparable area (MCA, as in Zhang 2010, p.94). The MCA takes into account the changing definition and division of municipalities throughout the years. Using the MCA as the unit of analysis lowers significantly the number of cities to account for and the complexity level of analysis: Brazil has 5,570 municipalities, but only 474 MCAs. Besides, in the case of Brazil there had been significant changes recently in the division of municipalities. We chose the municipality as our level of analysis because in the case of São Paulo there are only 645 municipalities, and because in our time frame (2011-2012) the definition of its cities did not change.

In order to construct our competitiveness index and each of its five dimensions, we transformed and normalized each of the 46 indicators so it would adapt to the interval $[0,1]$. We then used each variable's weight $\left(\mathrm{P}_{\mathrm{i}}\right)$ in each of the five dimensions as one $\mathrm{i}$-th of the total number of variables in that dimension, so that the index equals the following:

$$
\mathrm{I}_{\mathrm{i}}=\Sigma \mathrm{P}_{\mathrm{i}} \cdot \mathrm{Z}_{\mathrm{i}}
$$

whereas $I_{i}$ is the value for each of the five dimensions for a city, $P_{i}$ is the weight for that particular variable for that city, and $\mathrm{Z}_{\mathrm{i}}$ is the standardized value for that particular variable for that city calculated in the previous step. Thus, for each dimension, $P_{i}$ equal $1 / n$, where $n$ is the number of variables that comprised that dimension. The overall competitiveness index was calculated as the simple average of its five components. Finally, we ranked cities according to the overall competitiveness index and according to each one of the five different dimensions of competitiveness for the years 2011 e 2012 .

Now we turn to the methodology for the Exploratory Spatial Data Analysis (ESDA). We used the GeoDA software, using a shape file for the state of São Paulo and its 645 municipalities ${ }^{1}$. We then joined it with data from the ICM-SP, on the overall competitiveness index and on its five dimensions of competitiveness

1 The source of GIS maps and shape files is BRASIL (2014). 
(urban, sociodemographic, fiscal/institutional, economic and innovation) that were calculated in the previous section.

We first tested the hypothesis that spatial data are randomly distributed. That is, spatial randomness means that the values of an attribute in a region do not depend on the values of this attribute in the neighboring regions. To test the presence of global spatial autocorrelation, we used the Moran's I statistic (ALMEIDA, 2012, p.37).

We then tested for the presence of clusters of cities with high competitiveness and low competitiveness in the overall competitiveness index and in its five dimensions using LISA cluster maps. These maps (with the univariate local Moran's I indicators) provide groupings of data in the form of low-low, high-low, low-high and highhigh statistically significant associations ${ }^{2}$. Finally, we performed the spatial patterns analysis of the five dimensions of the competitiveness index.

\section{Results}

In this section, we present the results for the construction of the Competitiveness Index for the 645 Municipalities of the state of São Paulo (ICM-SP), as well as our results for the Exploratory Spatial Data Analysis (ESDA) of the ICM-SP. First, we start with the results for the construction of the ICM-SP; as mentioned earlier, we ranked cities according to the overall competitiveness index and according to each one of the five different dimensions of competitiveness for the years 2011 e 2012. Since we did not have significantly different results for both years, the results are displayed below for the year 2012. Figure 1 shows the spatial patterns of the overall ICM-SP competitiveness index for all cities by quintile.

Our first result is that the spatial pattern for overall ICM-SP in São Paulo coincides with the major economic, urban and road axes of the state. Thus, cities with higher competitiveness are located in the São Paulo Metropolitan Region (RMSP), in the Campinas Metropolitan Region, alongside the Anhanguera and Bandeirantes highways (towards Piracicaba-Americana-Limeira-Ribeirão Preto), alongside the Washington Luis highway (São Carlos-Araraquara-São José do Rio Preto), and alongside the Dutra highway (São José dos Campos-Taubaté). Besides,

2 To investigate whether there are local spatial patterns in the ICM-SP and each one of the its five dimensions, we generated univariate LISA cluster maps using only 2012 data, as the LISA maps for 2011 and 2012 did not vary significantly. Moreover, we used univariate maps only; for that same purpose, other authors have used bivariate LiSA cluster maps (as in MEINERS et. al. (2013), for example). 
we also noticed that the cities with the lowest competitiveness scores (marked in beige) tend to be located in the sounthernmost, easternmost, and westernmost parts of the state.

FIGURE 1

ICM-SP, by quintile, 2012

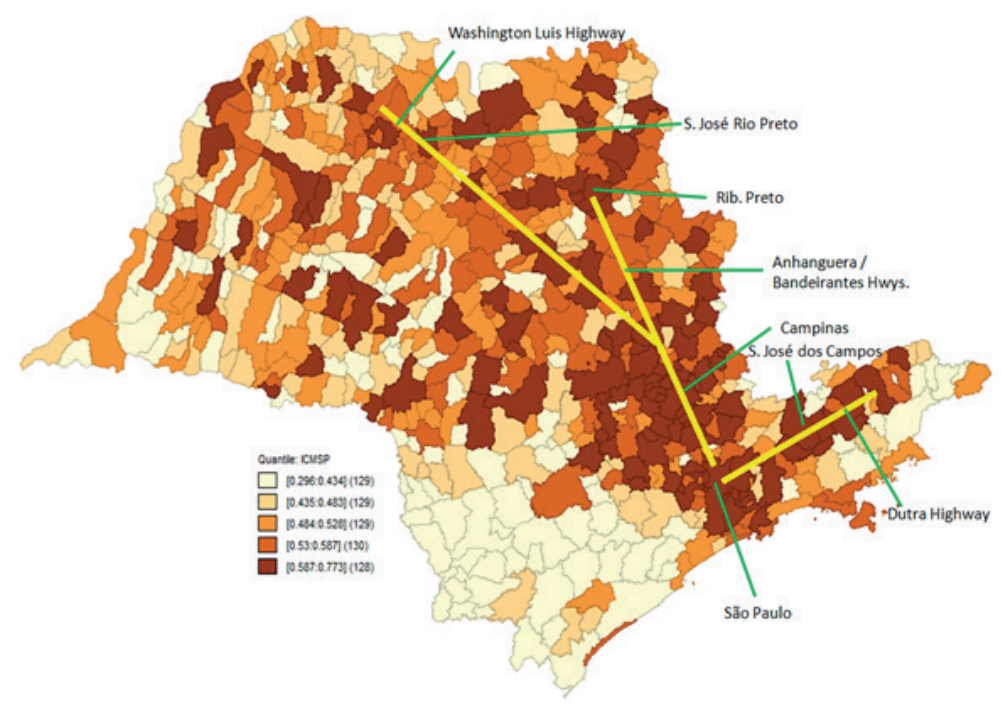

Source: Authors' calculations.

In Table 2 we present the top twenty cities ranked according to the overall competitiveness index and according to each one of the five different dimensions of competitiveness for 2012. Our results for the overall ICM-SP are as follows. Among the 20 main municipalities are: (a) the main economic centers of the state, which have the main advantages of urbanization and agglomeration, as well as the most advanced institutional structures (São Paulo and Campinas); (b) metropolitan municipalities that conform areas of industrial expansion (Barueri, São Caetano do Sul, São Bernardo do Campo and Santo André, but also Valinhos, Vinhedo, Indaiatuba and Paulínia); (c) cities with large enterprises and infrastructure with endogenous developments in the generation of services that promote expansion of local businesses and markets (such as São José dos Campos and Sorocaba); and (d) municipalities with a tradition of agricultural and agribusiness cooperatives (Piracicaba, Araraquara and São José do Rio Preto). Furthermore, when we look at the bottom 20 cities (not shown in Table 2) at the overall competitiveness index, 
we observe that most cities with low competitiveness are poorer towns located in the southern (known as the Vale do Ribeira region), western (known as Pontal do Paranapanema) and eastern (close to the border of the Rio de Janeiro state) parts of the state.

The city ranking for the ICM-SP in Table 2 also demonstrates that cities with the highest competitiveness indexes are mostly midsized cities ${ }^{3}$, such as São Caetano do Sul, Vinhedo Valinhos and Barueri, but some large cities such as São Paulo (the state's largest city), São José dos Campos and Jundiaí are well positioned in the ranking. In fact, those midsized cities are usually part of larger metropolitan areas led by one or more large cities. These results suggest that the competitive edge is located in midsized cities in large metropolitan areas. Indeed, this has also been the case in several countries recently, with second-rank cities having been identified as the main driving forces in national economic performance in Europe. Agglomeration economies are called upon to explain the relatively better performance of second-rank cities, while diseconomies of scale are identified as the cause of the limited success of large ones (DIJKSTRA et. al, 2013; PARKINSON et al., 2014). However, as we found that those midsized cities were usually part of a metropolitan area led by a large city, this suggest that it is possible to overcome diseconomies of scale by innovating in the functions cities perform (higher ranked functions) and by organizing activities with other cities (city networking); in this case, midsized cities can "borrow size" from neighbouring large cities in metropolitan areas, getting access to the level of functions and networks that cities have (CAMAGNI et al., 2014).

As we proceed to evaluate city performance in each of the five dimensions (results which are also presented in Table 2), we notice different patterns. In the urban and sociodemographic, only medium-sized (such as Barretos, Americana and São Caetano do Sul) and small cities (such as Nhandeara) appeared in the ranking. No large city performed well in the urban index. This has to do with the fact that large cities tend to have overstrained urban infrastructures. The same result emerged in the sociodemographic dimension, where midsized Vinhedo and small Cerquilho were among the top. This is due to the fact that large cities tend to suffer the most with larger migration inflows from poorer regions of the country, deteriorating their social indicators. In the case of the fiscal/institutional index, small and midsized towns again dominated the top of the list. These cities tend to have large flows

3 We classified the cities of São Paulo into three different groups: small cities (up to 50,000 inhabitants in 2013), medium cities (between 50,000 and 300,000 inhabitants) and large cities (over 300,000 inhabitants). 


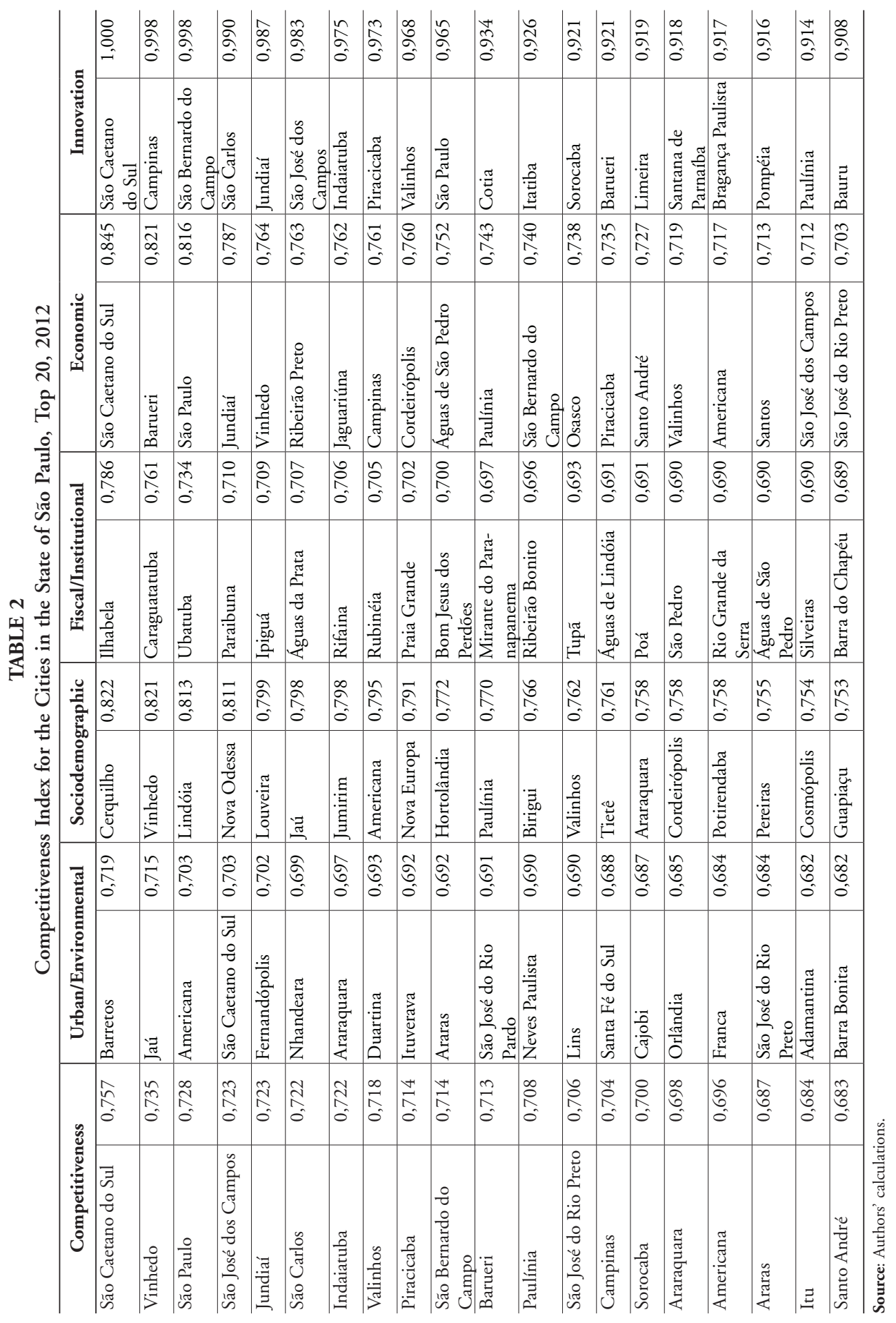


from the Municipal Participation Fund from the federal government and tend to have less expenditures on infrastructure and financial debts.

In the economic dimension both large and midsized cities performed well. Large industrial cities such as São Paulo, Jundiaí and Ribeirão Preto had good performance, but that is also the case of medium-sized cities as Barueri. Larger cities still maintain a sizeable industrial base, but they have been losing production capacity to cities of medium size within the state of São Paulo and also outside the state. As far as the innovation dimension is concerned, midsized cities such as São Caetano do Sul and large cities such as Campinas and São José dos Campos performed well. This is consistent with the presence of research institutes and renowned universities on those cities, as well as companies that have a tradition of high research and development investment.

We now turn to the analysis of the results for the Exploratory Spatial Data Analysis (ESDA) of the ICM-SP. First, we tested the hypothesis that spatial data are randomly distributed. We used the Moran's I statistic; in our case, the value of Moran's I (0.372) is higher than the expected value (minus 0.0015), providing clear indication that competitiveness is autocorrelated in space for the municipalities of the state of São Paulo. Furthermore, our results show that they are invariant with respect to the contiguous convention that is used in the construction of a spatial weights matrix ${ }^{4}$. Thus, there is evidence of positive spatial autocorrelation, that is, cities in the state of São Paulo with high (low) competitiveness are surrounded by municipalities with high (low) value of competitiveness, which suggests the presence of spatial clusters in the state.

Next, we tested for the presence of city clusters of high competitiveness and low competitiveness in the overall competitiveness index and in its five dimensions using LISA cluster maps. In Figure 2, we display the results for the overall competitiveness index for high-high clusters (marked in red). We notice that the cluster of municipalities with high competitiveness spill over from the São Paulo Metropolitan Region (RMSP) to the Campinas Metropolitan Region. There is also another cluster of high ICM-SP cities surrounding the city of Ribeirão Preto. Thus, around the São Paulo-Campinas axis and towards the cluster around Ribeirão Preto are the regions where the potential for competitiveness is higher due to factors that extrapolate the conditions of each municipality and are characterized as regional

4 As in Meiners et. al. (2013), for the purpose of choosing a spatial weights matrix, we tested the matrices of contiguity tower and queen and the matrices of k-neighbors, with $\mathrm{k}$ ranging from 1 to 20 . After running the regression several times using the different matrices, the one that generated the largest value of Moran's I as statistically significant was the matrix of contiguity queen. 
factors, potentializing the urban, sociodemographic, institutional, economic, and innovational conditions of each regional cluster.

FIGURE 2

Cluster Map for the ICM-SP, 2012

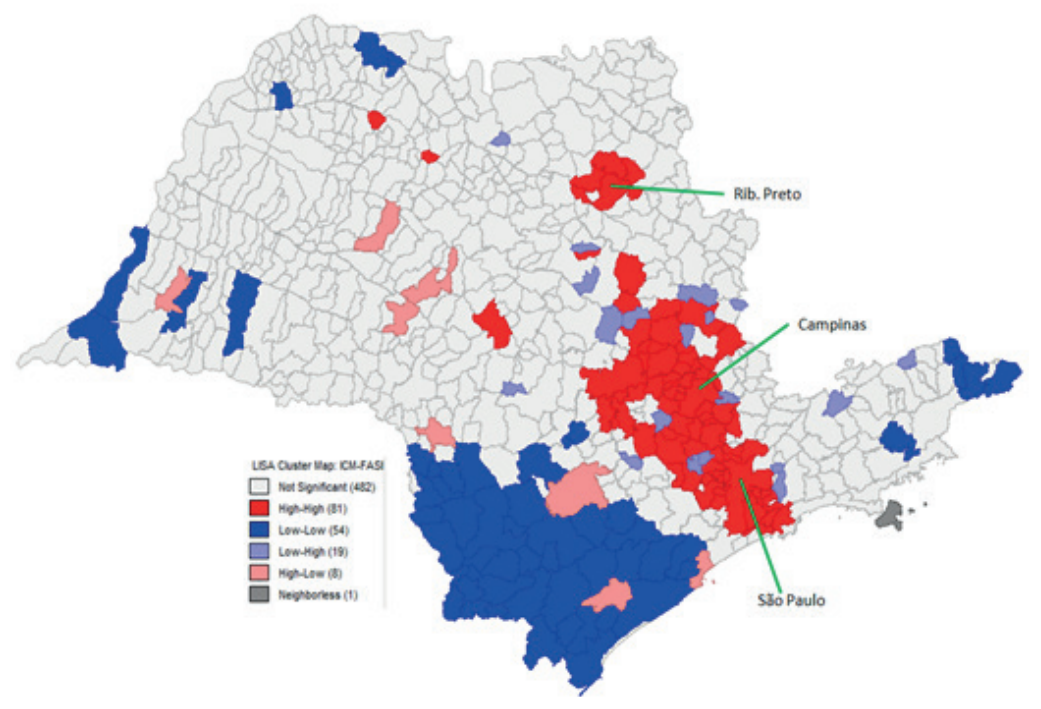

Source: Authors' calculations.

On the other hand, the analysis of low-low clusters for the ICM-SP displays three clusters of cities of low competitiveness surrounded by other cities of low competitiveness. In Figure 2 above, we exhibit such clusters marked in blue. They are located in the southernmost part of the state, in the easternmost part of the state, and in the westernmost part of the state, which are areas of low competitiveness performance (in line with what we observed above in the analysis for Table 2). These three regions have been the poorest areas of the state in recent years. Finally, the incidence of low-high and high-low cases are more isolated and are spread more homogeneously in the state's territory, that is, they do not concentrate in specific regions.

We now turn to the spatial patterns analysis of the five dimensions of the competitiveness index. Starting with the urban/environmental dimension (Figure 3 below), we notice three clusters of small and medium sized cities with high urban/environmental competitiveness (marked in red), one located 
in the north of the state, close to Ribeirão Preto, another in the state's center, close to Jaú, and another in the center-east, nearby Campinas. Those clusters of mainly small and medium cities tend to have less overstrained urban infrastructures. The clusters of low-low urban/environmental competitiveness (marked in blue) are located at the state's southernmost and easternmost regions, plus another around the northern shore of the state, where several poorer cities are located.

\section{FIGURE 3}

Cluster Map for the ICM-SP, Urban/environmental Dimension, 2012

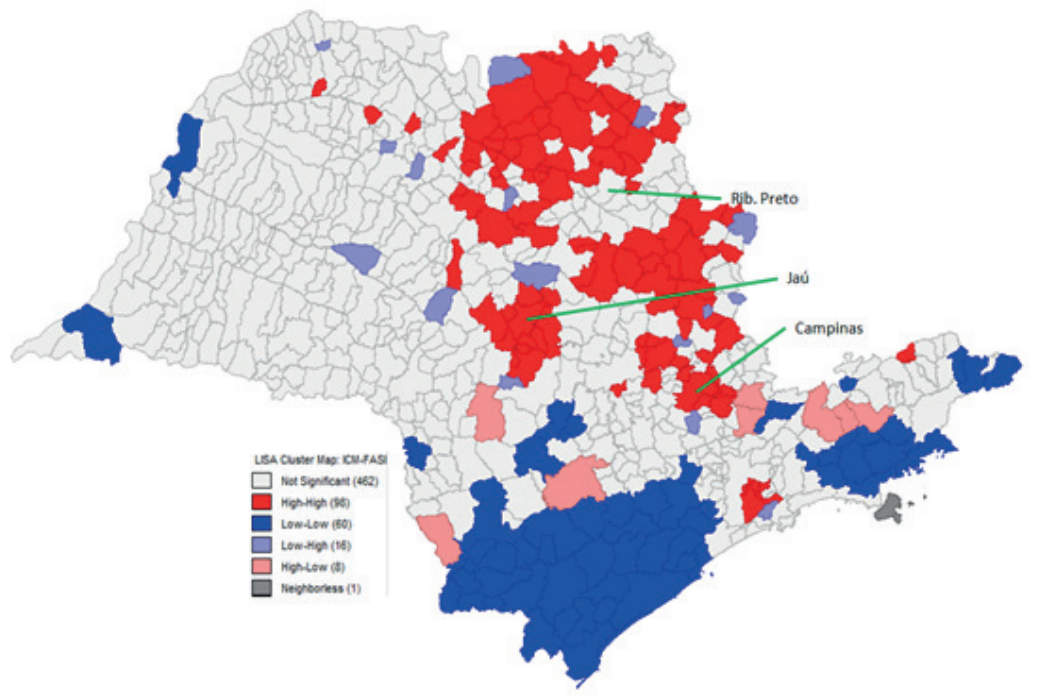

Source: Authors' calculations.

The LISA map for the sociodemographic dimension (Figure 4) shows clusters in the metropolitan regions of São Paulo, Campinas, São José do Rio Preto and Ribeirão Preto. The cities with higher scores in this dimension are mostly small and midsized cities in those metropolitan areas; those cities are less prone to suffer from migration inflows from poorer regions of the country compared to larger municipalities. Moreover, the clusters of cities with low sociodemographic competitiveness scores are once again concentrated in the poorer west, east and south of the state of São Paulo. 
FIGURE 4

Cluster Map for the ICM-SP, Sociodemographic Dimension, 2012

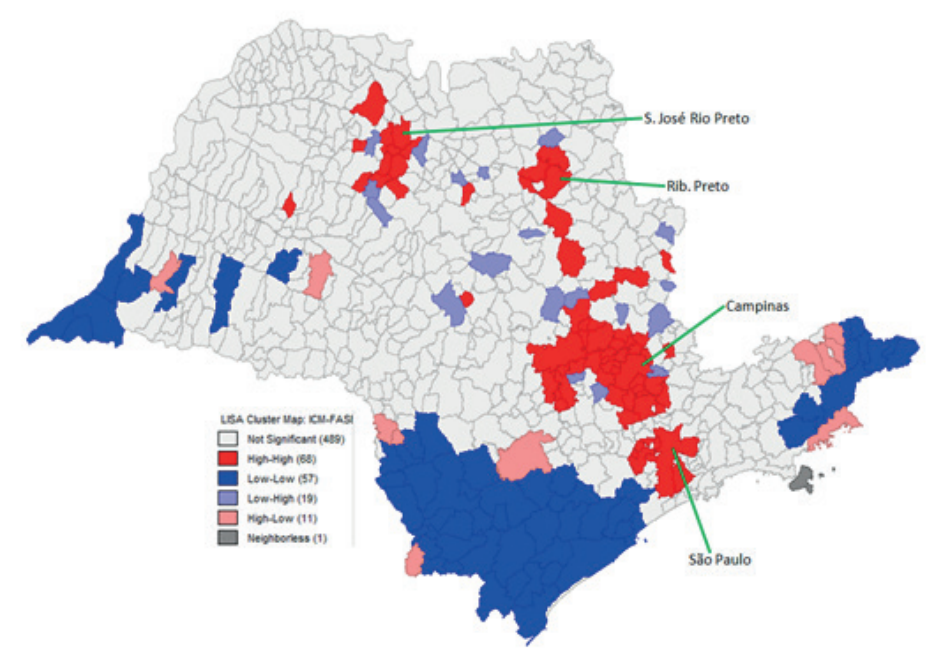

Source: Authors' calculations.

Regarding the institutional/fiscal dimension, in Figure 5 we notice that no significant cluster of cities have emerged, except for a cluster in the northern coast of the state (around the port town of São Sebastião). This pattern has to do with the fact that cities with high institutional/fiscal competitiveness scores are usually small, and they are spread throughout the state, even in the poorer regions of the far west, east and south. Small cities tend to have large flows from the Municipal Participation Fund from the federal government and tend to have less expenditures on infrastructure and financial debts, having in general a good fiscal position. Metropolitan areas of the state concentrate many large cities with lower positions on the fiscal/institutional index. As for the cities with low fiscal/institutional competitiveness, there were no clear spatial cluster patterns either.

In the case of the economic dimension (Figure 6), two clusters of cities with high competitiveness were located alongside an axis that connects the metropolitan regions of São Paulo and Campinas; besides, there were two small clusters around the cities of Ribeirão Preto and São José do Rio Preto. This is due to fact that these dynamic areas concentrate most of the industrial and agribusiness production in the state. As for the the cities with low performance in the economic dimension, a large cluster around the southern part of the state and another in the west showed that these areas exhibited reduced economic dynamism. These are regions based on subsistence farming and extractivism, with population losses due to the lack of employment prospect. 
FIGURE 5

Cluster Map for the ICM-SP, Fiscal/institutional Dimension, 2012

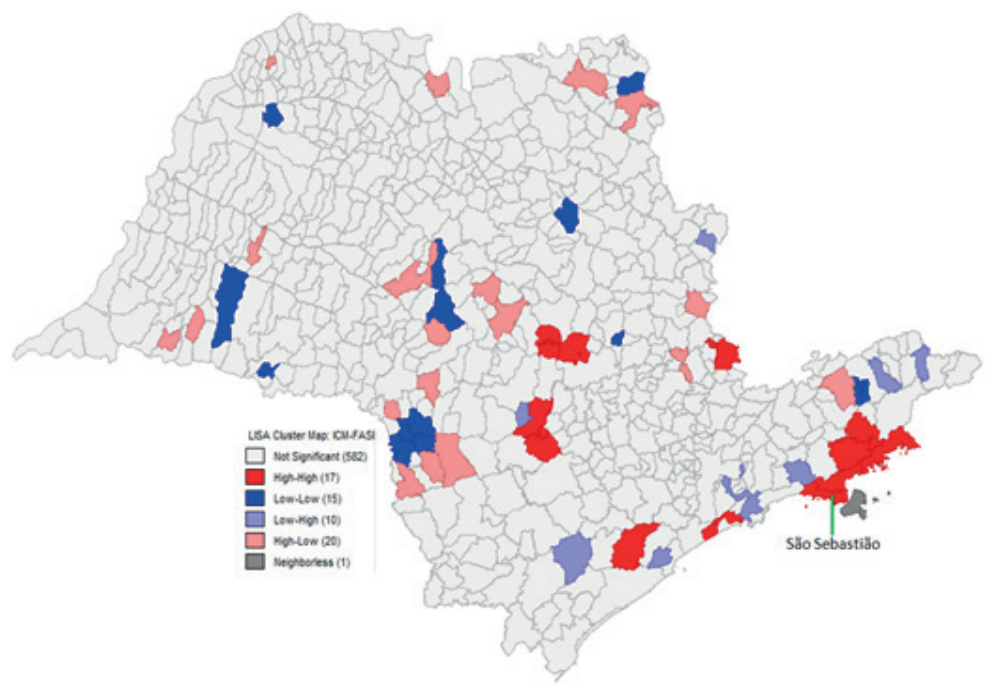

Source: Authors' calculations.

FIGURE 6

Cluster Map for the ICM-SP, Economic Dimension, 2012

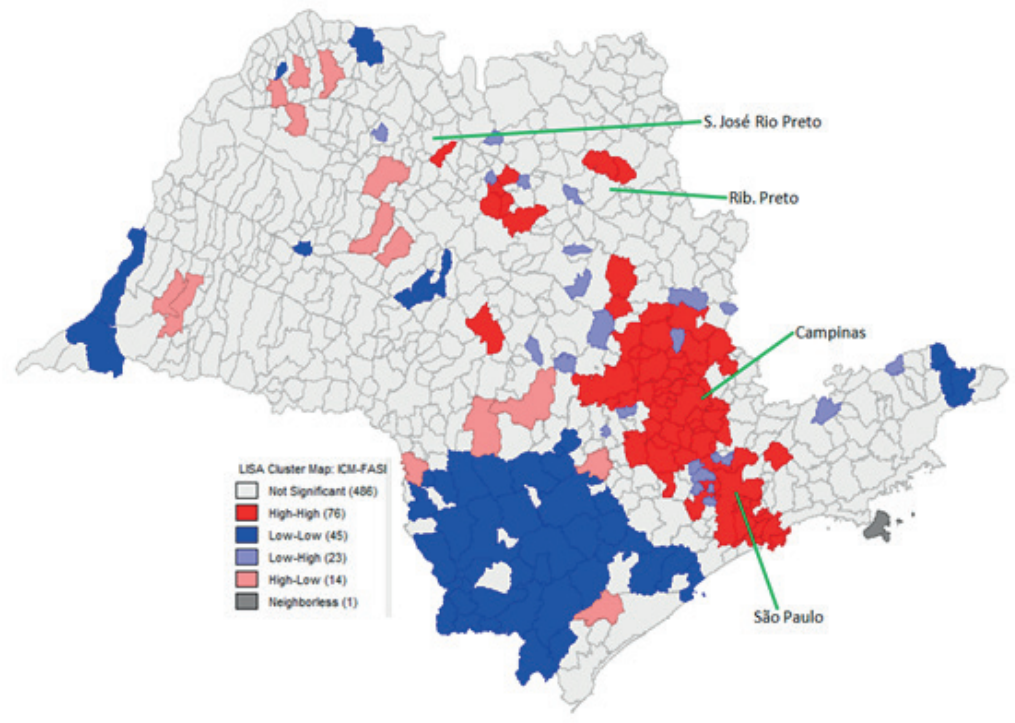

Source: Authors' calculations. 
Finally, in the case of the innovation dimension (Figure 7), the LISA map showed a cluster of cities with high innovation performance which spill over from São José dos Campos to São Paulo and to Campinas, plus another cluster surrounding Ribeirão Preto; in fact, those areas have hosted companies with tradition in research and development for a long time, as well as important research institutes and universities. On the other hand, clusters of cities with low innovation competitiveness were located in the southern and western parts of the state, as well as in the center of the state, areas which have traditionaly lacked a framework of research and development institutions.

FIGURE 7

Cluster Map for the ICM-SP, Innovation Dimension, 2012

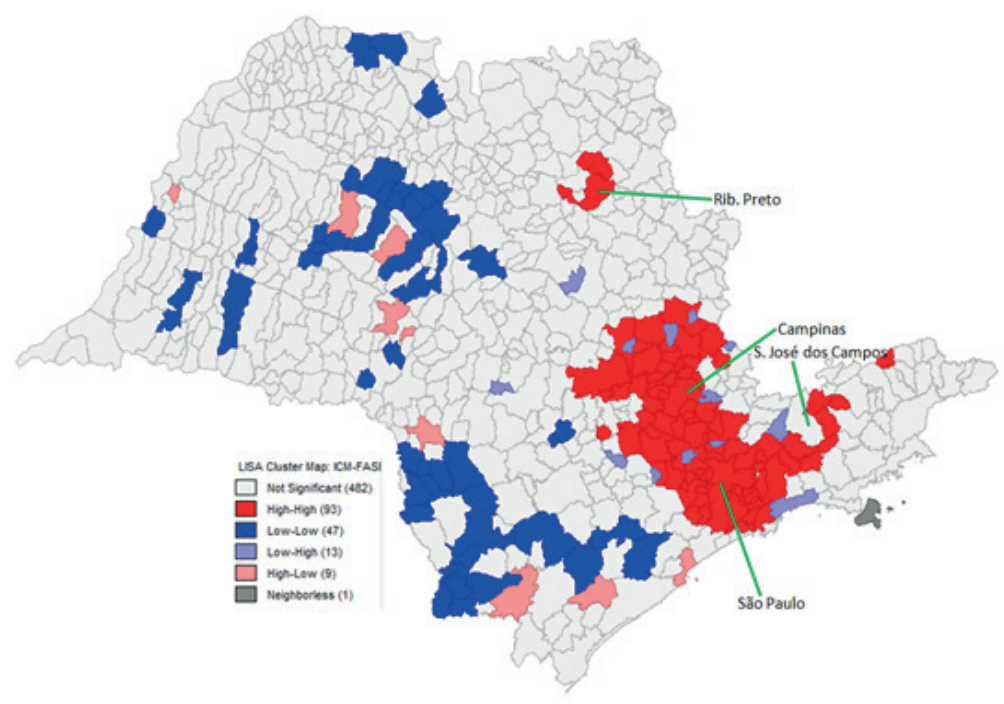

Source: Authors' calculations.

\section{Conclusions}

Businesses are facing an ever-fiercer competitive environment. If they are to compete internationally, cities and governments should create more favorable conditions for the economic agents that are located there. An important question that arises is how to view and measure the potential and performance of cities. We contribute to this 
debate by creating a competitiveness index for the 645 municipalities of the state of São Paulo (ICM-SP), the largest regional economy in Brazil.

Our ICM-SP includes five dimensions of competitiveness which represent the main important components of the business environment. Firms seek to locate in cities with good economic and financial structures (economic), a healthy and productive labor force (sociodemographic), good infrastructure and strong natural environment (urban/environmental), with strong institutions and favorable fiscal policies (fiscal/ institutional), in a skilled and innovative place (innovation). Compared to Zhang's (2010) benchmark work, we included a fifth dimension, innovation, as well as new indicators, such as institutional and environmental, not previously included.

Another contribution of this article is that we found that the role of spatial spillovers is important in the state of São Paulo; the results for the overall competitiveness index showed that cities with similar competitiveness tend to locate near each other, leading to the presence of spatial clusters. Furthermore, the importance of the ICM-SP and its disaggregation in five dimensions is that it allows identification of the areas for improvement as well as suggestion for the use of public policy to advance such areas in which a city does not excel in. Even though a city may be at the top of the overall ranking, it is not necessarily performing well across all components (ZHANG 2010, p.103). The spatial patterns of the ICM-SP exhibit the cities in the state of São Paulo with the best competitive environments for business development, and it serves as a reference for the promotion of local development policies.

We identified areas with low competitiveness in the southernmost, in the easternmost, and in the westernmost parts of the state. These three regions have been the poorest areas of the state in recent years; indeed, competitiveness there is low across four of the five dimensions of the index (all but the institutional/fiscal dimension). This is worrisome, as these regions may have more difficulty in attracting investment and jobs, and may face high unemployment rates and even emigration. Such a low competitiveness region can well be pushed "out of business"; in this scenario, taking care of the regional effects of stronger global competition bears a strong economic rationale (CAPELLO; FRATESI, 2013, p. 18). Thus, those three cluster areas should concentrate policy efforts on all three levels of government.

Finally, we provide evidence of the role of city size in explaining competitiveness. Our results suggest that the edge of competitiveness is in midsized cities which are part of larger metropolitan areas led by one or more large cities. This could be explained by the fact that midsized cities overcome diseconomies of scale by 
borrowing size from its larger neighbours in metropolitan regions, getting access to their level of functions and existing networks (CAMAGNI et al., 2014).

This study can be extended in several ways. First, in order to address more deeply the question of why the most competitive cities tend to be medium-sized cities linked to a large city in a metropolitan area, we need a spatial econometrics model that could explain the determinants of regional and local competitiveness, which would shed further light at the size in which agglomeration is relevant. In fact, we are currently working on an article that involves the specification of a spatial econometric model that considers the index of competitiveness for cities - controlled by size - of the state of São Paulo in relation to the five dimensions considered in this article. Moreover, we built a model that included data only from 2011 and 2012. A dynamic study could also be performed by building a spatial econometric model using panel data from previous years (such as the census years of 1980, 1991 and 2000), linking the space and time dimensions of competitiveness. Lastly, in the methodology section, for each of the five dimensions of competitiveness we attributed a weight $\left(\mathrm{P}_{\mathrm{i}}\right)$ as $1 / \mathrm{n}$ for each variable, in which $\mathrm{n}$ is the number of variables that comprised that dimension. Alternatively, it is possible to use the principal component analysis (PCA) method to estimate these weights.

\section{References}

ALBUQUERQUE, F. Desenvolvimento Econômico Local: caminhos para a construção de uma nova agenda politica. Rio de Janeiro: BNDES, 2001.

ALMEIDA, E. Econometria Espacial Aplicada. Campinas, SP: Átomo \& Alínea, 2012.

ANNONI, P.; DIJKSTRA, L. EU Regional Competitiveness Index 2013. JRC Scientific and Technical Reports, European Comission (EC), 2013.

BEGG, I. Cities and competitiveness. Urban studies, v. 36. N. 5/6, pp 795-810, 1999.

BRASIL (2014). Portal Brasileiro de Dados Abertos - dados.gov.br. Available at: http://dados. gov.br/dataset/malha-geometrica-dos-municipios-brasileiros/resource/93e3e2f0-e9fd-4cc1-af06-0046af19736f. Last access: May 2015.

CAMAGNI, R.; CAPELLO, R.; CARAGLIÙ, A. The rise of second-rank cities: what role for agglomeration economies? European Planning Studies, v.22, n.6: pp. 1069-89, 2014. 
CAMAGNI, R. On the Concept of Territorial Competitiveness: Sound or Misleading?. Urban Studies, v.39, n.13: pp. 2395-2411, 2002.

CANO, W. Desequilíbrios Regionais e Concentração Industrial no Brasil: 1930-1995. 2a ed. Campinas: Instituto de Economia da UNICAMP, 1998.

CAPELLO, R.; FRATESI, U. Globalization and Endogenous Regional Growth. In CRESCENZI, R.; PERCOCO, M. (eds.), Geography, Institutions and Regional Economic Performance - Advances in Spatial Science. Berlin: Springer-Verlag, pp 15-37. 2013.

CENTRO DE LIDERANÇA PÚBLICA (CLP). Brazil State-Level Business Operating Environment. Economist Intelligence Unit (EIU), 2013.

DA MATA, D.; DEICHMANN, U.; HENDERSON, J. V.; LALL, S. V.; WANG, H. G. Determinants of city growth in Brazil. Journal of Urban Economics, v.62, n.2: pp. 252-272, 2007.

DIJKSTRA L.; GARCILAZO E.; McCANN P. The economic performance of European cities and city regions: myths and realities. European Planning Studies, v.21, n.3: pp. 334-354, 2013. FEDERAÇÃO DAS INDÚSTRIAS DO RIO DE JANEIRO (FIRJAN). Índice FIRJAN de Desenvolvimento Municipal (IFDM), 2014.

FLORIDA, R. The Rise of the Creative Class: And How It's Transforming Work, Leisure, Community and Everyday Life. New York: Basic Books, 2002.

FUNDAÇÃO JOÃO PINHEIRO/PNUD/IPEA. Atlas do Desenvolvimento Humano no Brasil. 2013. Available at: http://atlasbrasil.org.br/2013/pt/consulta/. Last access: May 2015. FUNDAÇÃO SEADE. Informaçôes dos Municípios Paulistas (IMP) - 2011. Available at: http://produtos.seade.gov.br/produtos/imp/. Last access: May 2015.

GOIS SOBRINHO, E.M.; AZZONI, C.R. Potencial Inovativo da Indústria nas Regiões Brasileiras. Revista Brasileira de Inovação, v.15, n.2: pp. 275-304, 2016.

INSTITUTO BRASILEIRO DE GEOGRAFIA E ESTATÍSTICA (IBGE). Perfil dos $\mathrm{Mu-}$ nicípios Brasileiros 2013.

INSTITUTO NACIONAL DA PROPRIEDADE INDUSTRIAL (INPI). Números de Patentes por Municipio, 2011. Available at: http://www.inpi.gov.br/estatisticas. Last access: May 2015.

KOURTIT, K.; NIJKAMP, P.; SUZUKI, S. The rat race between world cities: In search of Exceptional Places by means of super-efficient data development analysis. Computers, Environment and Urban Systems. v. 38, pp. 67-77, 2013. 
KITSON, M.; MARTIN, R.; TYLER, P. Regional Competitiveness: An Elusive yet Key Concept? Regional Studies, v.38, n.9: pp. 991-999, 2004.

LANDRY, C.; BIANCHINI, F. The Creative City. London: Demos, 1995

MEINERS, W; ESTEVES, L.A.; LEITE, L.; RISSETE, C. Uma Análise Espacial do Índice de Desenvolvimento Municipal da Micro e Pequena Empresa (IDMPE) do Paraná. Revista Brasileira de Estudos Regionais e Urbanos, v. 7, n.2, p. 68-82, 2013.

MEINERS, W; ESTEVES, L.A.; LEITE, L.; FELIPPE, E. O Índice de Desenvolvimento Municipal da Micro e Pequena Empresa. In: Anais do VII Encontro Nacional da Associação Brasileira de Estudos Regionais e Urbanos, São Paulo, 2009.

MOVIMENTO BRASIL COMPETITIVO (MBC). Índice de Competitividade Estadual - Fatores (ICE-F). Brasília: MBC, 2006.

PARKINSON, M.; MEEGAN, R.; KARECHA, J. City size and economic performance: Is bigger better, small more beautiful or middling marvellous? European Planning Studies, v. 23, n.6, pp. 1054-1068, 2014.

PORTER, M. E. The Competitive Advantage of Nations. New York: Macmillan, 1990.

RELAÇÃO ANNUAL DE INFORMAÇŌES SOCIAIS (RAIS). Estatísticas - RAIS. Ministério do Trabalho e Emprego (MTE), 2013. Available at: http://portal.mte.gov.br/geral/ estatisticas.htm. Last access: May 2015.

THE ECONOMIST INTELLIGENCE UNIT (EIU). Hot spots 2025 - Benchmarking the future competitiveness of cities. Economist Intelligence Unit, 2013.

WORLD ECONOMIC FORUM (WEF). The Global Competitiveness Report 2014-2015. Geneva: WEF, 2014.

ZHANG, M. Competitiveness and Growth in Brazilian Cities. Washington: World Bank, 2010 